\title{
INVESTIGACIÓN
}

Recibido: 04/03/2020 --- Aceptado: 26/05/2020 --- Publicado: 12/03/2021

\section{REFLEXIONES PROPOSITIVAS PARA LA EDUCACIÓN UNIVERSITARIA EN CRIMINOLOGÍA}

\section{Propositive reflections for university education in criminology}

(D) $87 R^{a}$ Wael Sarwat Hikal Carreón ${ }^{1}$. Universidad Autónoma de Nuevo León, México. wael.hikalcrr@uanl.edu.mx

\section{RESUMEN}

En el presente artículo se reflexionan y propone sobre cuatro aspectos que se consideran pueden mejorar sobre el estado actual de los estudios universitarios en criminología en México. Se introduce al lector en los orígenes de la Licenciatura en Criminología a nivel universitario por la necesidad de formar a un profesional que atendiera lo inherente a la investigación criminal, penitenciaria, pericial y preventiva, mismas necesidades que dieron principio a sus salidas profesionales en los comienzos de esta profesión. También se repasa brevemente las materias que componen los planes de estudio, dando visión de los alcances que puede tener esta profesión. Visto lo anterior, se realizan cuatro propuestas: 1) Cambios a nivel legislativo para "reconsiderar" salidas laborales; 2) especializar a la criminología general en ramas sobre problemas criminales específicos; 3) fortalecer la investigación generadora de conocimientos en materia criminal para los analistas delictivos y planificadores de políticas públicas, y 4) el fortalecimiento a las prácticas pedagógicas y contenidos formativos.

PALABRAS CLAVE: especialización - docencia - investigación - reforma normativa - perfiles laborales.

\section{ABSTRACT}

This article reflects and proposes on four aspects that are considered to be improving on the current state of university studies in criminology in Mexico. The reader is introduced to the origins of the Bachelor of Criminology at the university level

\footnotetext{
${ }^{1}$ Wael Sarwat Hikal Carreón: Doctorando en Filosofía con Acentuación en Estudios de la Educación por la Facultad de Filosofía y Letras, Universidad Autónoma de Nuevo León, México. Correo electrónico: wael.hikalcrr@uanl.edu.mx
} 
because of the need to train a professional who would attend to the inherent in criminal, prison, expert and preventive research, the same needs that gave principle to their professional outings in the beginning of this profession. It also briefly reviews the subjects that make up the curricula, giving insight into the scopes that this profession can have. In view of the above, four proposals are made: 1) Changes at the legislative level to "reconsider" job departures; 2) specialize general criminology in branches on specific criminal problems; 3) strengthen knowledgegenerating research in criminal matters for criminal analysts and public policy planners, and 4) strengthening pedagogical practices and training content.

KEYWORDS: labour profiles - legal reform - research - specialization - teaching.

\section{REFLEXÕES PROPOSITIVAS PARA A EDUCAÇÃO UNIVERSITÁRIA NA CRIMINOLOGÍA}

\section{RESUMO}

No presente artigo se reflexiona e se propõe quatro aspectos que se consideram que possam melhorar o estado atual dos estudos universitários na criminologia no México. Se introduz ao leitor nas origens da Licenciatura em Criminologia a nível universitário pela necessidade de formar um profissional que atendesse o inerente a pesquisa criminal, penitenciária, pericial e preventiva, mesmas necessidades que deram começo a suas saídas profissionais nos inícios desta profissão. Também se repassa brevemente as matérias que estão contidas nos planos de estudo, dando visão das possibilidades que pode ter esta profissão. Tendo em conta o anterior, são feitas 4 propostas: 1) Mudanças a nível legislativo para "reconsiderar" saídas laborais; 2) especializar a criminología geral em ramos sobre problemas criminais específicos; 3) fortalecer a pesquisa geradora de conhecimentos em matéria criminal para os analistas de crime e planejadores de políticas públicas, e 4) fortalecer as práticas pedagógicas e conteúdos formativos.

PALAVRAS CHAVE: Especialização- docência - ensino - reforma normativa - perfis laborais.

\section{Cómo citar el artículo:}

Hikal Carreón, W. S. (2021). Reflexiones propositivas para la educación universitaria en criminología. Vivat Academia. Revista de Comunicación, 154, 85-100. http:/ / doi.org/10.15178/va.2021.154.e1221

http://www.vivatacademia.net/index.php/vivat/article/view/1221

\section{INTRODUCCIÓN}

La solución a los problemas sociales y de criminalidad mundial que se padecen actualmente, se encuentran en parte en las intervenciones que los profesionales y planificadores de políticas públicas realicen, esto, debe estar basado en la medida de sus capacidades intelectuales, compromiso y responsabilidad social, y de pertinencia 
que tengan (Bonifacio Barba, 2018). Entre las múltiples profesiones relacionadas con la intervención en conflictos de orden social, se encuentra la criminología, como ciencia social cuyo fin último es la procuración de la paz (Medina Wahnnatah; Almada Quintero; Duarte Félix y Avalos Wahnnatah, 2018).

Los iniciadores de la criminología, depositaron y confiaron en su progreso las labores de intervenciones ante los fenómenos de la criminalidad (Ordaz Hernández y Figueroa Castellano, 2017) que en esta época, a nivel global, se acrecientan las secuelas de problemas que no se han superado, además de nuevos problemas emergentes en el evolucionar de los sistemas sociales, por lo que se tienen dos esquemas: 1) La acentuación de problemas aún no culminados y que se arrastran desde un momento histórico particular, y, 2) nuevas formas de criminalidad que aprovechan las tecnologías de la comunicación y transmisión de información.

Empero a aquella esperanza vertida en la criminología, no se ha logrado ver su transformación e impacto social (Mampaso Desbrow, Seoane Ruíz; Pérez Fernández y Martín-Moreno Blasco, 2016) como se había esperado, incluso se sigue aguardando. Esto ha originado más problemas además de los suscitados anteriormente, la falta de reconocimiento profesional y laboral del criminólogo de formación a nivel licenciatura, así como escaso desarrollo de investigaciones que permitan generar un conocimiento para los alumnos en formación, como para los planificadores de políticas sociales (Rodríguez Jorge; Pérez Gonzáles; Zambrano Intriago y Palma Caicedo, 2016). La escuela tiene la tutela de formar líderes sociales, encaminados al éxito, pero ante todo, al compromiso social (Organisation for Economic Co-operation and Development, s.f.).

Hoy, como nunca antes, es necesario cuestionar y replantear los objetivos generales de la criminología, sus procesos de enseñanza y la pertinencia social de la misma (Cantú Mendoza, 2015). Se requiere configurar un mapa con posibles intervenciones académicas y administrativas (Giménez-Salinas, 2009), para fortalecer a la criminología como parte de las ciencias sociales, para que de resultados de acuerdo a las expectativas y urgencias de la sociedad (Avendaño, 2019).

El objetivo general del presente es aportar la perspectiva sobre la condición académica de los estudios universitarios en criminología en México. Se inicia mostrando el nacimiento de los estudios universitarios en criminología y las características de impartición, y su expansión en otras regiones a nivel institucional y programas educativos; sus salidas profesionales $y$ contenidos formativos. Posteriormente, se plantean una cuatro de propuestas que se podrían implementar para mejorar la pertinencia interna y externa. De tal forma, se puntualiza en cuatro propuestas específicas sobre las que se puede generar un mapa de posibilidades a trabajar para mejorar: 1) Reforma legislativa para los perfiles laborales del criminólogo; 2) especialización en áreas concretas sobre fenómenos específicos; 3) fortalecimiento a la investigación, y 4) fortalecimiento a la docencia.

\section{DISCUSIÓN}

Vivat Academia. Revista de Comunicación. 2021, n 154, 85-100 
En México, la educación superior de la criminología ha tenido un importante incremento en los últimos años, en alrededor de entre 5 a 10 años, han proliferado abundantemente las instituciones educativas que imparten esta enseñanza al ser novedosa (Hikal Carreón, 2020), pero su crecimiento no ha significado el avanzar de la mano con la calidad educativa (Bonifacio Barba, 2018), La experiencia sobre las nuevas modalidades criminales, el uso de la tecnología como medios para ejercer la delincuencia de muy variadas formas (Navasquillo Lorda, 2016), la pertinencia e impacto social (Cantú Mendoza, 2015). Su crecimiento se debe principalmente a razones comerciales, ha ocurrido un boom por estudiar esta profesión, pero tampoco es correlacional la cantidad con los resultados sociales, ocurrió una demanda sustentada en el interés social detectado (Mampaso Desbrow, Seoane Ruíz; Pérez Fernández y Martín-Moreno Blasco, 2016). Cruelmente: “El crimen vende, estas titulaciones son muy "sexy", y su popularidad entre jóvenes estudiantes está casi garantizada" (Medina, 2012, p. 20).

Cabe plantearse ¿Para qué era necesario crear una Licenciatura en Criminología? “¿Cuáles son las funciones qué como profesional le compete al criminólogo? ¿Cuáles son las materias que debe conocer un criminólogo para su futura actividad laboral?" (Navasquillo Lorda, 2016, p. 5). Ríos Patio (2017), podría aportar una respuesta útil al contemplar lo que parece irremediable e incontenible: "la existencia de índices alarmantes de criminalidad en el país, que acusan tendencias de crecimiento, amenaza el orden social, la gobernabilidad del estado y la unidad de la nación" (p. 72). Con ello, se justifica en parte la necesaria creación de un profesional que investigue todo aquello vinculado con las causas del crimen de manera social, política, económica, individual, histórica, mental, física, además de agregar las funciones de investigación forense (Rodríguez Jorge; Pérez González; Zambrano Intriago y Palma Caicedo, 2017).

De principio, los estudios de criminología en México, surgen dentro de otros grados, que en alguna vertiente se pudiera ocupar del estudio criminal, por ejemplo, se revisa a la criminología en las materias de derecho penal, ciencias penales, psicología u otras, así como estudio de violencia, no propiamente atribuidos a la criminología (Hikal Carreón, 2020). Podía y aún se estudia en especialidades, maestría o doctorados, "su formación siempre estuvo en un limbo doctrinal que muchas veces era complicado de llegar a entender" (Navasquillo Lorda, 2016, p. 2) hasta que se desmembró como grado independiente, pero persiste una tendencia a ubicarla junto al derecho (Ordaz Hernández y Figueroa Castellano, 2017).

Pasado el tiempo, luego de una espera de 100 años desde que se considera el nacimiento de la criminología con la publicación del Tratado Antropológico Experimental de Lombroso, posteriormente, se comenzó a divulgar a través de artículos, obras y congresos (Hikal, 2019). “Esto significa que a pesar de que los estudios de criminología tienen una amplia tradición en el sistema educativo, su oficialización y regulación se produce muy tardíamente" (Mampaso Desbrow, et. al., 2016, p. 77). 
Exactamente, en México, 45 años atrás, la criminología se convirtió en licenciatura, con duración de inicio de 4 años, luego se agregó uno más, y quedo a la par de otros grados como el de derecho, psicología, ingenierías, etcétera. En las escuelas privadas, el rango es de 3 años, algunas escuelas han hecho la increíble labor de titular en un año y medio, otras la han ingresado como bachillerato técnico, e incluso ya, estudios en línea. Existen dos polos, muchas escuelas privadas ofertan la licenciatura, pero pocas públicas. Tal vez un directorio completo sería el Censo de centros escolares y programas educativos en criminología, criminalística, victimología y carreras afines en México (Hikal Carreón, 2020).

La primer Licenciatura en Criminología nace en la Universidad Autónoma de Nuevo León, en su concepción se atribuyó el estudio del delito, el delincuente, la pena, la prevención del delito, rehabilitación penitenciaria y la investigación forense de los hechos delictuosos (Cámara Arroyo, 2019; Acosta Muñoz, 2017), por lo que se estableció dentro de la antigua Facultad de Derecho y Ciencias Sociales, hoy Facultad de Derecho y Criminología (Hikal, 2019), lo que desde sus inicios, en México, se legó la tradición de colocar los estudios superiores de criminología en áreas afines al derecho, lo que deriva en el estudio jurídico del delito (Medina Wahnnatah; Almada Quintero; Duarte Félix y Avalos Wahnnatah, 2018).

La creación de la licenciatura se generó en el seno de un grupo de académicos que deseaban contribuir con soluciones desde el campo universitario para formar profesionales especializados en la materia criminal (Giménez-Salinas, 2009), superando a los investigadores empíricos, para llevar un aspecto con mayor profesionalización, capacidad técnica y científica. La principal razón no fue improvisación u ocurrencia académica, obedecía a la creciente criminalidad que se generaba en el país, logrando su consolidación en 1974. En su momento, obedeció a razones académicas, profesionales y científicas (Ordaz Hernández y Figueroa Castellano, 2017).

Después de este hecho, sin tener un orden sistemático de aparición de las posteriores escuelas que decidieron crear otras licenciaturas en criminología (y criminalística o ciencias forenses), se fueron estableciendo desde entonces y hasta la fecha en gran cantidad de escuelas privadas, superando más de 400, por el contrario, pocas escuelas públicas: Universidad Autónoma de Nuevo León, Universidad Autónoma de Tamaulipas, Universidad Popular Autónoma de Veracruz, Universidad Autónoma de San Luis Potosí, Universidad Autónoma de Querétaro, Universidad Autónoma de Puebla, Universidad Autónoma de Tlaxcala, Universidad de Guadalajara, Universidad Nacional Autónoma de México, y Universidad Autónoma de Baja California Sur (Hikal Carreón, 2020). El requisito de ingreso a estas, es obligado el kardex de de estudios de preparatoria, no existen equivalencias, excepto los estudios abiertos o titulaciones exprés, pero del mismo grado de preparatoria (Giménez-Salinas, 2009). 
Estas anteriores, ofrecen el grado de licenciatura, otros grados superiores son las especialidades, maestrías y doctorados también en criminología, criminalística, ciencias forenses, penales, criminales, $u$ otras, no se dispone de la cuantificación de grados de especialidad y maestría, pero de doctorado, son pocas las escuelas que lo ofertan, comenzando con las escuelas públicas: Instituto Nacional de Ciencias Penales, Universidad Popular Autónoma de Veracruz, y Universidad Autónoma de Nuevo León. Las privadas son: Instituto Zacatecano de Estudios Universitarios, Consejo Mexicano de ciencias Jurídicas y de la Salud, Universidad Alva Edisión y Universidaf Humani Mundial y Centro de Estudios Avanzados de Veracruz (Hikal Carreón, 2020). El requisito para ingresar a estos estudios son de licenciatura, exclusivamente o su equivalencia de otro país.

A todos estos estudios los revisan y autorizan la Secretaría de Educación Pública (2020) a nivel federal, adicionalmente, en su autonomía, los demás estados que componen a la república mexicana, a través de sus secretarías de educación, también pueden evaluar y autorizar el grado de licenciatura, especialidad, maestría y doctorado, con validez en todo el territorio nacional, teniendo dos miras: 1) La escuela de cualquier región otorga el título, mientras que 2) es función exclusiva de la secretaría federal, el otorgamiento de la licencia del grado para su ejercicio. El financiamiento de estos estudios corresponde al alumno que ingresa, puede tener subsidio de la escuela pública o privada para obtener cuotas más económicas. La carga lectiva ha variado de entre 3 horas por día durante la semana, a seis, ocho, doce o 24 horas en sábados y/o domingos, tanto para licenciatura como otro grado superior (Hikal Carreón, 2020).

Para obtener el grado de licenciatura, especialidad, maestría o doctorado, se requiere elaborar una tesis, anteriormente era obligado, pero hace algunos años, se sustituyó esta práctica por tomar diplomados, materias, inscribirse a estudiar la maestría en la misma institución o realizar la tesina (que comprende una sistematización más corta), lo que ha limitado la contribución de resolver casos de manera escrita a través de un documento que refiere a la capacidad del postulante para investigar, documentar, sistematizar y exponer oral y físicamente, el resultado de su investigación. Cuya meta sería también, contribuir con esos resultados a otros al consultar su referente.

Aunque es alta la demanda por los estudios de la criminología (y afines), el mercado laboral no es abierto a los egresados (Cámara Arroyo, 2019). Quienes se colocan principalmente en dos áreas: Servicios de investigación forense públicos o privados, a través de peritajes cuando el particular lo busca y requiere, retribuyendo un pago por el estudio pericial que realice para refutar el que elabore el perito al servicio del estado y postularlo ante un juez, o si es en lo público, a través de las agencias del estado que requieran de estudios en varias ramas de la criminalística, que en diversas escuelas, se estudia dentro del grado de criminología (Hikal Carreón, 2020). 
Otro rubro es el de la seguridad privada (Cámara Arroyo, 2019), donde se emplean los criminólogos para las investigaciones internas, aplicación de polígrafo, detección de riesgos, protección de instalaciones, personas u objetos, vigilancia, seguimiento, evaluación de vulnerabilidades, establecer las medidas de prevención, contención, evitación, esto puede ser en el ámbito empresarial o de modo particular, con lo cual, la criminología corporativa ha tenido un gran auge en México, dentro de las pocas criminologías especializadas.

Pero no solo estas dos áreas son donde más se emplea a criminólogos, también en el área de las fuerzas de seguridad, ya sea en campos policiales de acción en campo, o en inteligencia, seguimiento, estrategias preventivas o interventivas. En México, el sistema carcelario depende de las secretarías de seguridad, por lo que el criminólogo también tiene salida laboral en las cárceles, para integración del diagnóstico de factores de riesgo psicológicos, sociales, seguimiento de su tratamiento penitenciario, detección de riesgos, integración social, familiar (Acosta Muñoz, 2017).

Otros tantos se ocupan en el ámbito docente o administrativo escolar, en la formación de otros profesionales que estudian las mismas áreas (Medina, 2012). Muy pocos, de primer carrera se dedican a la investigación científica, esta es liderada por criminólogos de segunda carrera; es decir, licenciados en derecho, psicología, medicina, sociología u otras, con estudios posteriores o de segundo grado en criminología. Las prácticas docentes han consistido en la repetición de técnicas antiguas que parecen novedosas para los estudiantes nuevos, mientras que también, los docentes no se basan en doctrinas teóricas contemporáneas (Avendaño, 2019).

Los mapas curriculares en cualquier grado, se nutren hasta ahora de las ciencias que con mayor antigüedad a la criminología fueron abordando a la criminalidad, algunas que nacieron casi a la par (Ordaz Hernández y Figueroa Castellano, 2017) o posteriormente también son tomadas para la nutrición de la criminología, por ejemplo: Antropología, psicología, psiquiatría, política, sociología, estadística, geografía, trabajo social, derecho, biología, entre otras, estas se enmarcan en los estudios convergentes a la criminología, mientras que para criminalística, en el caso de los centros escolares que en una misma licenciatura llevan ambas áreas, se alimenta de aquellas ramificaciones forenses: Toxiología forense, psiquiatría, psicología, sexología, lingüística, química, medicina, pediatría, ginecología, antropología, arte, valuación, pedagogía, dactiloscopia, grafoscopia, balística, entre muchas más. Aquí parece extraño que se ha potenciado más el desarrollo de las ciencias forenses que de las criminales; es decir, se genera más conocimiento para intervenir posterior al delito que para preverlo, pero no lo mismo en el ámbito penitenciario.

\section{REFLEXIONES Y PROPUESTAS}

Las experiencias del pasado, pueden ser vistas como posibilidades de aprendizaje para el mejoramiento continuo, de los errores se aprende también y da lugar a cambiar prácticas, ver donde se está fuerte, o flaco para hacer mejor las cosas, hay 
que hacer cosas diferentes a las tradicionales rutinas, en algunas se falla, en otras se tendrá éxito (Vences Esparza; Juárez Villalobos y Flores Alanis, 2016). Cuatro son los aspectos en los que se centrarán las reflexiones y propuestas, las cuales implican voluntad, y deseo de hacer las cosas diferentes:

1) reforma legislativa para reposicionar a los egresados de criminología y ubicarlos salidas laborales pertinentes;

2) especialización de la criminología general a ramas específicas;

3) fortalecimiento a la investigación,

4) fortalecimiento a la docencia.

Estas áreas que han sido obstaculizadas o poco desarrolladas, y son a la vez, las posibilidades para impulsar. Señala Navasquillo Lorda: "La criminología como Ciencia Social joven está en proceso de cambio, y necesita de un rigor académico que hasta la fecha no ha tenido" (2016, p. 1). Así, se plantean estas cuatro áreas de propuesta para el cambio y transformación interna en los contenidos académicos de la criminología, así como en los científicos, y un paso más, sería el impacto legislativo que tendría si fuera mayormente reconocida y postulada en diversos campos de acción y salidas laborales.

\subsection{Reforma legislativa para reorientar los perfiles laborales}

Es necesario el emplear a los criminólogos en los ayuntamientos, gobiernos, empresas ¿Para qué? Para atender aquellas vulnerabilidades y riesgos que estimulen la conducta criminal. Oportunamente, Ríos Patio (2017), reflexiona sobre cierta indiferencia por parte de los gobiernos para buscar soluciones: "La búsqueda de las causas de la criminalidad, que constituye la finalidad de la criminología, es un verdadero problema nacional" (p. 72). Expone que no se nota una vinculación entre los aportes de la criminología y los planificadores e implementadores de la política social. Esto se respalda en la reflexión también de Zaffaroni (1990), al indicar que esos conocimientos son necesarios para a los agentes de gobiernos y sector privado, para que estos se nutran de lo que desconocen e implementen lo adecuado para reducir, controlar, prevenir, investigar lo que circunda al crimen (Gaete Quezada, 2015).

Continuando con la reflexión de Ríos Patio (2017): “dicha ciencia social no está extendida en su desarrollo investigativo ni en su praxis en la política pública" (p. 72), esto en cuanto que parece que existe urgencia de lo visible, cuantificable, medible objetivamente, de manera inmediata, negado lo que venga a largo plazo o que la población no descifre más allá de inversiones de miles de monedas, equipo para persecución, castigo, contención, represión, fomentando en la construcción de la realidad social el aparentar hacer a través de la inversión pública en temas materiales y sobre todo, de castigo, exclusión, aislamiento de la sociedad a aquel que le ocasione un menoscabo. Concluye el drástico final de la realidad que nos acompaña en un régimen político "sin que interese prevenir dichas conductas para reducirlas estadísticamente, sino únicamente sancionar algunas de ellas" (Ríos Patio, 2017, p. 72). 
El cambio legislativo es de relevante importancia para dar directriz sobre qué puestos puede ejercer el criminólogo más allá de los tradicionales heredados, y que permita ampliar su actividad e injerencia, o sea, "establecer mecanismos que reajusten las promulgaciones legislativas a las necesidades del mercado" (Mampaso Desbrow, Seoane Ruiz; Pérez Fernández y Martín-Moreno Blasco, 2016, p. 73). En México, hay campos de trabajo donde es opcional el estar titulado, mientras que otros que tienen repercusión legal, es obligado estar licenciado para emitir opiniones, avalar estudios, etcétera; por ejemplo, un arquitecto no podría valuar un inmueble sin su licencia para tal efecto. Por otro lado, sería impensable que un ingeniero fuese ministerio público o fiscal, para ello se ha legalizado que únicamente aquel que posea el grado básico superior de Licenciado en Derecho, no ingeniero con grado de maestría en derecho industrial, ni médico de licenciatura con grado de especialidad en medicina legal, sino exclusivamente Licenciado en Derecho.

Así, hay que "fomentar entre las administraciones públicas y las instituciones privadas el uso de criminólogos como profesionales en beneficio de la Sociedad" (Navasquillo Lorda, 2016, p. 1), proponiendo en las cámaras legislativas la inclusión de los criminólogos en sitios donde pueda haber un brote de criminalidad, alguna situación de riesgo, vulnerabilidad en los grupos. La violencia y la criminalidad son temas de los que no se ha visto librada casi cualquier área de la vida, en los estadios deportivos, en las elecciones políticas, en la administración del fisco, en la cibervida, en el sistema de vida de los condominios, en el transporte aéreo, terrestre, en las escuelas, entre tantos, a lo que siempre se busca quién detecte, identifique, medie, controle, prevenga, aquellos actos espontáneos o planificados que afectan al colectivo (Cámara Arroyo, 2019).

En México, no es obligatorio que para las áreas laborales donde ha ganado campo el criminólogo, deba ser este profesional de estudios de licenciatura, sino que cualquiera con un conocimiento proximal o de segundo (maestría) o tercer grado (doctorado), reemplaza a aquel, pero no ocurre al revés; es decir, un Licenciado en Criminología, no sustituye a un abogado, ni psicólogo, ni médico, o sociólogo. Establecer las facultades legales y campos de acción que podría tener un criminólogo y elevarlo a rango legislativo, sería la base de los sistemas laborales del actuar, qué hacer y dónde hacerlo, del criminólogo. Con ello se revertiría la tendencia a la incertidumbre, al fracaso laboral, donde apenas se ofertan unas cuantas vacantes. En el momento actual, las legislaciones no cuentan con una figura profesional del criminólogo (Avendaño, 2019). Navasquillo Lorda (2016) expone dos cuestiones: “¿Qué objetivo tiene acreditar unos estudios universitarios como los de Criminología cuando el propio Estado cierra las puertas a un desarrollo profesional?" (p. 5).

\subsection{Especialización sobre fenómenos específicos}

Se considera que la especialización de la criminología, permitirá tener herramientas para los problemas concretos de la sociedad. El desarrollo intelectual de la criminología se ha quedado atorado o estancado, son aquellas ciencias que se 
mencionaron las que realizan estudios criminales, y permiten una visión holística del fenómeno, pero no se ven muchos estudios que emanen del interior de la misma criminología (Ordaz Hernández y Figueroa Castellano, 2017). No se niega la gran utilidad de las aportaciones que las ciencias han realizado ni de la criminología general, el conocimiento de cada área y las bases teóricas y conceptuales, llenan de un saber amplio visto desde enfoques, "pero más aún es entregarnos al saber concreto de aquellas especialidades que a futuro puedan darnos una oportunidad profesional" (Navasquillo Lorda, 2016, p. 2).

En la medida en que la criminología general se concrete en campos específicos, las capacidades intelectuales y oportunidades laborales del criminólogo, se ampliarán, no es fácil encontrar a los criminólogos en México en las áreas que estos asumen son en las que deberían estar, y que también se les ha transmitido en las aulas, las salidas laborales son limitadas (Cámara Arroyo, 2019), pues la tradición de otras profesiones y su utilidad técnica, les han consolidado en trabajos específicos, de los cuales, la criminología no ha logrado empoderarse (Medina Wahnnatah; Almada Quintero; Duarte Félix y Avalos Wahnnatah, 2018). Es fácil predecir en el conocimiento vulgar o del hombre de la calle, para qué funciona un abogado, un médico, un psicólogo, pero hay vaguedad sobre qué puede hacer un criminólogo, lo que incluso en los departamentos de reclutamiento, limita las oportunidades ante la ignorancia.

Afirma Navasquillo Lorda "en ningún caso podemos olvidar aspectos tan importantes como los científicos, la investigación criminológica, la globalización, las nuevas tecnologías, los campos innovadores de estudio, y la especialización de los conocimientos" (2016, p. 3). El criminólogo debe actualizar su marco teórico sobre las tendencias contemporáneas de la criminalidad, y esto se logrará a través de la investigación. Estar preparado para recibir los avances educativos que le permitan desarrollar conocimiento, capacidades, actitudes y adaptación al cambio complejo del mundo (Organisation for Economic Co-operation and Development, s.f.).

De tal modo, la recompensa de especializarse tiene dos funciones: 1) Mejor conocimiento disponible para los planificadores de políticas sociales, 2) y más variadas salidas laborales (Cámara Arroyo, 2019), no limitantes ni estigmatizadoras a los rubros exclusivamente policiales, forenses, detectivescos (Avendaño, 2019). Se trata de modo muy puntual en proponer criminologías específicas a fenómenos especiales, desarrollar de inicio con pequeñas monografías, tesis universitarias, o extrauniversitarias, darles un título que encuadre en algún campo específico, y desmenuzarlo con un subtítulo. "La publicación de estos trabajos serían de gran ayuda al ser una herramienta importante para el aporte de conocimiento científico (Navasquillo Lorda, 2016, p. 4).

Aquello que se escucha sobre transdiciplina, hay que buscarlo, integrando los conocimientos de otras ciencias y transfórmarles, dirigirlos, especializarlos a lo criminal y todas las aristas que se deriven, factores causales, origen de la conducta en el individuo, en sociedad, variantes, tratamiento, prevención (Rodríguez Jorge; Pérez González; Zambrano Intriago y Palma Caicedo, 2016). Entonces se estará en 
posibilidad de sustituir, pero sin abandonar, dar paso de una sociología criminal a una criminología sociológica, de una psicología del desarrollo anormal, a una criminología psicológica, de una seguridad privada a la criminología laboral, crear nuevas nomenclaturas, abrirse espacios, tanques de conocimiento, oportunidades laborales, praxis profesional (Rodríguez J. 2016).

\subsection{Fortalecimiento a la investigación}

La tradición de investigación para la titulación mediante tesis o tesina, se viene diluyendo con otras opciones de salida del centro escolar y la obtención del grado. Tal vez ha ocasionado un menoscabo el no guiar a los alumnos a que sus resultados, podrían ser sistematizados y expuestos públicamente a través de libros, artículos o capítulos en libro, incluso exposiciones o docencia, puesto que el estudiante desea fervientemente egresar para insertarse en el campo laboral sin retornar contribuciones a la escuela que lo formó o a otras generaciones (Acosta Muñoz, 2017).

Es importante mantener la instrucción en método, técnicas, organización de la información y exposición, al no tener de vuelta en las aulas los conocimientos que se generan en el campo práctico, ocurre "que la Criminología se está impartiendo como una ciencia social alejada de la realidad práctica de sus contenidos" (Navasquillo Lorda, 2016, p. 3), y la vez su carácter científico es dudable e indefendible ¿Cómo se ciencia sin científicos ni generadores de conocimiento? ¿Sin comprobar resultados? ¿Sin planteamientos epistemológicos, filosóficos? (Di Claudo, 2013). Estamos en la presencia de una criminología lenta, sin resultados inmediatos ante las nuevas manifestaciones criminales, que debe esperarse a lo que las demás ciencias logren investigar. Navasquillo Lorda estipula: “en ningún caso podemos olvidar aspectos tan importantes como los científicos, la investigación criminológica, la globalización, las nuevas tecnologías, los campos innovadores de estudio, y la especialización de los conocimientos" (2016, p. 3).

La investigación es la vía para lograr la especialización y los cambios legislativos, para que un abogado ocupe el cargo de fiscal qué requirió antes, un conocimiento especializado, sólido, y un soporte legal, donde se establece que únicamente, de todo el universo de profesiones, el abogado, es de manera exclusiva, el que puede ostentar el cargo de fiscal. Para el ejercicio de la medicina pediátrica, qué se requiere, una sólida doctrina que establezca bases de operación de las funciones del médico en el área con los menores, una serie de técnicas, estudios, comprensiones, casos, ejemplos (Rodríguez J. 2016). No podría atribuirse que un criminólogo podría ocupar cargos de ministerio público sin tener la argumentación penal suficiente, tampoco que este pueda realizar una intervención para con menores, si no conoce qué áreas debe atender. Por otro lado, de una abundante argumentación tendrá las bases para defender su labor, y hacer notar lo necesaria que es la profesión, de tal modo que impacte en las legislaturas. "En ese sentido, el trabajo investigativo se justifica porque siendo los fines esenciales del estado el bienestar general y la seguridad integral" (Ríos Patio, 2017, p. 72). 
Mientras tanto, el criminólogo no puede extender su influencia en otros campos en los cuales no está facultado legalmente, y tampoco teórica y prácticamente (Acosta Muñoz, 2017). Algunos podrán no convencerse del desarrollo especializado, bastará con ver los resultados que genera el desarrollo científico en relación al progreso de la sociedad. Puede que las escuelas encuentren dificultad en comprometerse a actividades de investigación por la falta de conocimiento sobre cómo realizarlo, o por recursos, pero al contrastar los efectos de la investigación con las evidencias de resultados, la resistencia puede cambiar. Los centros educativos debe ser abiertos a explorar los restos y oportunidades que la sociedad cambiante provoque, la mundialización de los cambios también (Organisation for Economic Co-operation and Development, s.f.).

\subsection{Fortalecimiento docente}

Un tema anexo, se considera el de la enseñanza, como se mencionó, los contenidos de la criminología son variados, con parcelas de los campos que han tenido mismo interés de estudio, pero con diferentes puntos de vista. Un docente con suficiente respaldo teórico y pragmático, podrá aportar a los alumnos en formación, conocimientos contrastados con las diferentes realidades culturales (Organisation for Economic Co-operation and Development, s.f.). Ocurre en ocasiones que se improvisan materias sin soporte suficiente para llenar los contenidos necesarios por ver. Se encuentran planes de estudio con manuales básicos que no se editan más, no se consiguen o vienen de otros países, sin que se reste importancia a esto, pues ofrece la mirada global que la criminología comparada aporta, pero a problemas locales, soluciones desde lo local (Gaete Quezada, 2015).

Se debe fortalecer la docencia con prácticas que involucren a alumnos, docentes, incluso padres, y los sectores comerciales, qué requiere el mercado laboral y social (team learning), para crear necesidades y oportunidades en común, saber trabajar en equipo, organizados, con normas y valores. Un equipo comprometido en identificar los temas relevantes y prioridades para aprovechar al máximo las oportunidades que se detecten. Los docentes deben estar preparados y guiar prácticas y enseñanzas ante los cambios abruptos del presente siglo XXI (Organisation for Economic Cooperation and Development, s.f.). Los estudios en criminología podrían estructurarse en:

- No abandonar los conocimientos que aportan las ciencias de convergencia en lo criminal, continuar nutriéndose de la antropología, sociología, derecho, etcétera, "siempre con la premisa clara de que sirvan para establecer unos cimientos sólidos sobre la materia" (Navasquillo Lorda, 2016, p. 4).

- La especialización de las criminologías en campos, ramas, sectorizando los conocimientos, huyendo a la aglomeración y acumulamiento indiscriminado de saberes en lo que llamamos "criminología general". Así como la biología se ha ramificado en celular, del desarrollo, botánica, molecular, fisiológica, $\mathrm{u}$ otras, así como la sociología rural, del trabajo, de la música, educativa, 
económica, política, industrial, etcétera, las criminologías específicas, deben emerger. El médico busca especializarse profesionalmente, el abogado también, el antropólogo, el biólogo, el criminólogo del futuro podrá lograrlo, teniendo amplias oportunidades entre tantos problemas criminales, cada problema específico, debe tener, soluciones específicas (Navasquillo Lorda, 2016).

- Vincularse con las instituciones públicas y privadas para estar en posición de realizar prácticas profesionales y que los alumnos aprendan a hacer e implementar lo que en el aula le han enseñado. También, que la escuela cuente con laboratorios adecuados para la simulación de actividades aplicativas. Incluso, sostener ejercicios fuera de las aulas, el laboratorio más grande con el que se cuenta es la misma sociedad, donde de manera rutinaria, ocurren fenómenos (Vences Esparza; Juárez Villalobos y Flores Alanis, 2015).

- La ética criminológica debe ser base fundamental en todas las materias de estudio, concientizando y fomentando el respeto a la vida, muerte, sufrimiento, víctimas, casos con los que se trate, se convierten en sujetos de estudio, pero no son móvil para llevarnos a una fama efímera producto de lo espectacular que resulta el crimen en notas periodísticas, series de televisión, $\mathrm{u}$ otros (Medina, 2012).

\section{CONCLUSIONES}

Se mostraron los orígenes de los estudios universitarios en criminología en México a razón de la necesidad de formar profesionales capacitados en los fenómenos de la criminalidad desde los aspectos causales, penitenciarios, seguridad pública, periciales, entre otros. Desde el comienzo de la primera institución que creó la licenciatura, al paso de los años proliferaron otros centros educativos que crearon programas educativos en la materia, ello trajo también áreas de oportunidad para observar en un proceso de mejorar permanente en relación a la pertinencia interna y externa. El presente se concretó en reflexionar y proponer sobre cuatro temas, el primero, las salidas profesionales, desde un aspecto que aborda reformas para replantear y reorientar las funciones y aplicaciones de la criminología y los profesionales de esta, el segundo rubro, fue el estímulo a la investigación de problemas específicos y modernos de la criminalidad contemporánea, que llevó al tercero, para acrecentar el corpus teórico disponible para comprender y abordar los fenómenos, el último tópico, el cuarto, enfocado a fortalecer la docencia, concretándose en la bibliografía, prácticas pedagógicas, interdisciplina, especialización, vinculación, ética, praxis, entre otras. Es la escuela, la que tiene un rol toral en la formación de los futuros profesionales de la criminología. Las licenciaturas en criminología ya existen, pero no se debe comprometer su calidad por la demanda tan grande que existe en el mercado por los interesados en ingresar a esta profesión, cuestiones relevantes deben atenderse, un marco sólido e integrados que basifique a las escuelas y su enseñanza superior, planes de estudio actualizados a las realidades sociales, contenidos bien argumentados, abundantes en manuales de referencia, docentes bien preparados en la teoría y práctica, sin que una se sustituya 
por la otra, áreas de investigación que aporten respuestas a los fenómenos emergentes de la sociedad, que instruyan e involucren a los alumnos en las actividades de sistematización y construcción del conocimiento.

\section{REFERENCIAS}

Acosta Muñoz, D. (2017) Investigación criminal en el medio penitenciario, en Investigación Criminal, 1(1), 58-69.

Avendaño, C. (2019). La criminología como espacio formativo necesario en Argentina. Debate Universitario. 8(15).

http://ppct.caicyt.gov.ar/index.php/debateuniversitario/article/view/16988/45454575769243

Di Caudo, M. V. (2013). La ciencia pedagógica: construcciones, disputas, desafíos. Sophia. Colección de Filosofía de la Educación, 14, 33-50. https://www.redalyc.org/pdf/4418/441846099003.pdf

Cámara Arroyo, S. (2019). La labor del criminólogo: Crítica a su falta de implementación laboral en España. Derecho y Cambio Social, 55. https://lnx.derechoycambiosocial.com/ojs-3.1.1-

4/index.php/derechoycambiosocial/article/view/29/10

Cantú Mendoza, R. (2015). Nuevos retos a la gestión de la educación superior en México. En Cantú Mendoza, R. (coord). La Responsabilidad Social de las Universidades Contemporáneas (pp. 13-38). San Nicolás de los Garza: Universidad Autónoma de Nuevo León y Editorial Itaca.

Bonifacio Barba, J. (2018). La calidad de la educación. Los términos de su ecuación. Revista Mexicana de Investigación Educativa. 23(78), 963-979. https://www.comie.org.mx/revista/v2018/rmie/index.php/nrmie/article/view $\angle 1184 / 1167$

Gaete Quezada, R. (2015). El gobierno y la gestión universitaria como ámbito de aplicación de la responsabilidad social, en: Cantú Mendoza, R. (coord) La Responsabilidad Social de las Universidades Contemporáneas: 143-156. San Nicolás de los Garza: Universidad Autónoma de Nuevo León y Editorial Itaca.

Giménez-Salinas, E. (2009). Libro Blanco Sobre El Título De Grado En Criminología. https://criminologiacys.files.wordpress.com/2017/08/libro-blanco-sobre-eltc3adtulo-de-grado-en-criminologc3ada.pdf

Hikal Carreón, W. S. (2020). Censo de centros escolares y programas educativos en criminología, criminalística, victimología y carreras afines en México. San Nicolás 
de los Garza: Sociedad Mexicana de Criminología capítulo Nuevo León. https://drive.google.com/file/d/13cs7uy8-Okezddai4Bd94IH1ENISPtmO/view

Hikal, W. (2019). Introducción a la Criminología Moderna y Especializada. Ciudad de México: Editorial Porrúa.

Mampaso Desbrow, J., Seoane Ruiz, A., Pérez Fernández, F., y Martín-Moreno Blasco, C. (2016). Pasado y presente legislativo de los estudios de grado en criminología en España: Soluciones y cuestiones pendientes. Revista de Comunicación Vivat Academia, 135, 73-84. http:// www.vivatacademia.net/index.php/vivat/article/view/981/1054

Medina, J. (2002). Reflexiones críticas sobre la futura Licenciatura en Criminología, Revista Electrónica de Ciencia Penal y Criminología, 4(15), 1-30. http://criminet.ugr.es/recpc/recpc04-15.pdf

Medina Wahnnatah, A., Almada Quintero, M. G., Duarte Félix, C. y Avalos Wahnnatah, V. (2018). La criminología como ciencia interdisciplinaria y su relación con el derecho penal. Revista de Investigación Académica sin Frontera, 27, 1-9. http://revistainvestigacionacademicasinfrontera.com/inicio/wpcontent/uploads/2018/06/27-1.pdf

Navasquillo Lorda, E. (2016). Los nuevos retos de la educación superior en criminología. I Congreso Internacional en Formación, Investigación e Innovación Educativa. Libro de Actas. http://www.iecis-edu.com/educacion-superior-encriminologia/

Neuman, E. (1990). El estudio de la criminología en Latinoamérica y la necesidad de $\begin{array}{llll}\text { soluciones } \quad \text { Egúcticas. } & \text { 269-286. }\end{array}$ https://www.ehu.eus/documents/1736829/2164896/24++ El+estudio+de+la+criminologia+en+latinoamerica.pdf

Ordaz Hernández, D. y Figueroa Castellano, J. (2017). Hacia una criminología $\begin{array}{llll}\text { contemporánea. Vox 33(1), 113-122. } & \text { Juris, }\end{array}$ https://dialnet.unirioja.es/descarga/articulo/6058758.pdf

Organisation for Economic Co-operation and Development (s.f.). What makes a school a learning organisation? A guide for policy makers, school leaders and teachers.

http://www.oecd.org/education/school/school-learningorganisation.pdf

Rodríguez J. N. M. (2016). Características y tipologías de la investigación en ciencias sociales: una reflexión sobre la complementariedad de las funciones de transformar y comprender. Universitas Humanística, 81, 357-385. https://www.redalyc.org/pdf/791/79143218014.pdf 
Rodríguez Jorge, R. R., Pérez González, E., Zambrano Intriago, G. Z. G., y Palma Caicedo, T. (2016). La criminología como ciencia interdisciplinaria en las investigaciones criminales y forenses actuales. Revista Magazine de las Ciencias, 1(3), 1-16. https://revistas.utb.edu.ec/index.php/magazine/article/view/62/234

Ríos Patio, G. (2017). La herencia de la criminología clínica. Horizonte Médico, 17(2), 71-76. Recuperado de https:// www.redalyc.org/pdf/3716/371651249011.pdf

Secretaría de Educación Pública (2020). Información de Reconocimientos de Validez Oficial de Estudios del tipo Superior (RVOES). https://www.sep.gob.mx/es/sep1/SIRVOES

Vences Esparza, A., Juárez Villalobos, G. y Flores Alanis, I. M. (2015) La vinculación universitaria en el marco de la responsabilidad social en la UANL. Apuntes para redimensionar esta función, en: Cantú Mendoza, R. (coord) La Responsabilidad Social de las Universidades Contemporáneas: 67-86. San Nicolás de los Garza: Universidad Autónoma de Nuevo León y Editorial Itaca.

Zaffaroni, E. R. (1990). La enseñanza universitaria de la criminología en América Latina. Eguzkilore. Cuaderno del Instituto Vasco de Criminología. 3, 59-71. https://www.ehu.eus/documents/1736829/2164896/08+-

+La+ensenanza+universitaria+de+la+criminologia.pdf

\section{AUTOR}

\section{Wael Sarwat Hikal Carreón}

Doctorando en Filosofía con Acentuación en Estudios de la Educación por la Facultad de Filosofía y Letras (becario CONACYT) de la Universidad Autónoma de Nuevo León.

wael.hikalcrr@uanl.edu.mx

Orcid ID: https:/ / orcid.org/0000-0003-1278-567X

Google Scholar: https://bit.ly/3nTm2Ew

Research Gate: https://www.researchgate.net/profile/Wael-Sarwat-Hikal-Carreon 